\title{
Resolving Radiological Classification and Release Issues for Many DOE Solid Wastes and Salvageable Materials
}

by

R. C. Hochel

Westinghouse Savannah River Company

Savannah River Site

Aiken, South Carolina 29808

This paper was prepared in connection with work done under the above contract number with the U.S. Department of Energy. By acceptance of this paper, the publisher and/or recipient acknowledges the U. S. Government's right to retain a nonexclusive, royalty-free license in and to any copyright covering this paper, along with the right to reproduce and to authorize others to reproduce all or part of the copyrighted paper. 


\section{DISCLAIMER}

This report was prepared as an account of work sponsored by an agency of the United States Government. Neither the United States Government nor any agency thereof, nor any of their employees, makes any warranty, express or implied, or assumes any legal liability or responsibility for the accuracy, completeness, or usefulness of any information, apparatus, product or process disclosed, or represents that its use would not infringe privately owned rights. Reference herein to any specific commercial product, process or service by trade name, trademark, manufacturer, or otherwise does not necessarily constitute or imply its endorsement, recommendation, or favoring by the United States Government or any agency thereof. The views and opinions of authors expressed herein do not necessarily state or reflect those of the United States Government or any agency thereof.

This report has been reproduced directly from the best available copy.

Available for sale to the public, in paper, from: U.S. Department of Commerce, National Technical Information Service, 5285 Port Royal Road, Springfield, VA 22161

phone: (800) 553-6847

fax: (703) 605-6900

email: orders@ntis.fedworld.gov

online ordering: http://www.ntis.gov/ordering.htm

Available electronically at http://www.doe.gov/bridge

Available for a processing fee to U.S. Department of Energy and its contractors, in paper, from: U.S. Department of Energy, Office of Scientific and Technical Information, P.O. Box 62, Oak Ridge, TN 37831-0062

phone: (865)576-8401

fax: (865)576-5728

email: reports@adonis.osti.gov 


\section{DISCLAIMER}

Portions of this document may be illegible in electronic image products. Images are produced from the best available original document. 


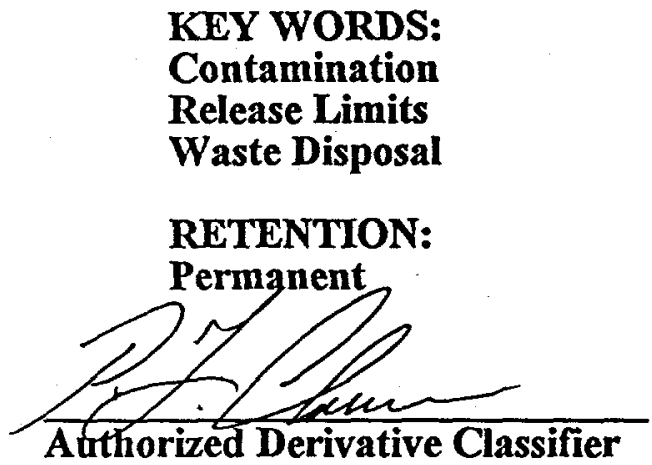

\title{
Resolving Radiological Classification and Release Issues for Many DOE Solid Wastes and Salvageable Materials (U)
}

\author{
R. C. HOCHEL \\ Westinghouse Savannah River Company \\ Savannah River Technology Center \\ Aiken, SC 29808
}

August 27, 1999

This report was prepared as an account of work sponsored by an agency of the United States Government. Neither the United States Government nor any agency thereof, nor any of their employees, makes any warranty, express or implied, or assumes any legal liability or responsibility for the accuracy, completeness, or usefulness of any information, apparatus, product, or process disclosed, or represents that its use would not infringe privately owned rights. Reference herein to any specific commercial product, process, or service by trade name, trademark, manufacturer, or otherwise does not necessarily constitute or imply its endorsement, recommendation, or favoring by United States Government or any agency thereof.

The views and opinions of the author expressed herein do not necessarily state or reflect those of the United States Government or any agency thereof. 


\begin{abstract}
The cost effective radiological classification and disposal of solid materials with potential volume contamination, in accordance with applicable U.S. Department of Energy (DOE) Orders, suffers from an inability to unambiguously distinguish among transuranic waste, low-level waste, and unconditional-release materials in a generic way allowing in-situ measurement and verification. Depending on a material's classification, disposal costs can vary by a hundred-fold. With these large costs at risk, the issues involved in making defensible decisions are ripe for closer scrutiny. In many cases, key issues can be easily resolved by a combination of process information, some simple measurements, and calculational predictions from a computer model for radiation shielding.
\end{abstract}

The proper classification and disposal of many solid wastes requires a measurement regime that is able to show compliance with a variety of institutional and regulatory contamination limits. Ultimate responsibility for this, of course, rests with radiological control or health physics organization of the individual site, but there are many measurements which can be performed by operations and generation organizations to simplify the process and virtually guarantee acceptance. Although this is not possible for all potential solid wastes, there are many that do lend themselves to such measures, particularly some of large volumes and realizable cost savings. Mostly what is needed for this to happen are a few guiding rules, measurement procedures, and cross checks for potential pitfalls. Several examples are presented here and discussed that demonstrate the possibilities, including one which was successfully applied to bulk contamination.

The only barriers to broader uses of this approach are workable and reliable procedures. For many issues and materials, the measurement tools are available; they need only be applied.

\title{
Introduction
}

The cost effective radiological classification and disposal of solid materials with potential volume contamination, in accordance with applicable U.S. Department of Energy (DOE) Orders, suffers from an inability to unambiguously distinguish among transuranic waste, low-level waste, and unconditional-release materials. Radiological control groups are authorized to make such calls, but they the frequently lack all the personnel and equipment to do so on a broad basis. There is no reason, however, why parts of the task cannot be shared by those having the most to gain from earlier and easier solutions. There is an enormous financial incentive to do this because, depending on a material's classification, disposal costs can vary by a hundred-fold across the three types. In addition, removing excess materials or wastes from facilities lessens exposure and improves safety in ongoing operations.

For years, there has been a near moratorium on the disposal of nearly all wastes with any potential volume contamination because of the lack of generic contamination limits to directly verify classification and disposal compliance. But new clarification and guidance for DOE Order 5400.5 [1] (and proposed 10 CFR Part 834), "Radiation Protection of the Public and Environment", allows the use of special limits in lieu of authorized limits, which may be 
WSRC-TR-98-00300

Revision 2

approved by local DOE Operations Offices. Already, specific personnel instructions for documenting material history and survey requirements for the radiological release of materials on a conditional or unconditional basis, consistent with 10 CFR 835, "Occupational Radiation Protection", are in place at the Savannah River Site (SRS) [2]. Therefore, a framework for dealing with volume-contaminated solid waste issues now exists, but unfortunately a workable program and complete procedures for appropriate measurements do not.

This paper, based on successful experiences at SRS, and a few literature reports from other DOE sites or the commercial sector, specifies the essential elements such a program should possess from a nuclear materials measurement perspective. Implementation of any site program, naturally, must be worked out to the satisfaction of all stakeholders, but the best starting point is for all to know that most of the technical measurement challenges and limitations can be overcome.

A simple, yet conservative, approach to classifying materials is to hypothetically assume all potential internal and external contamination is uniformly distributed on the outside surface of the material or its package. This pseudo contamination level, expressed in units of $\mathrm{dpm} / 100 \mathrm{~cm}^{2}$ can then be compared to the nearly-generic authorized surface limits of 10 CFR 835 . If the pseudo level is below the surface limits, the material is an excellent candidate for further release considerations. If not, the level can be useful for classification or other disposal options. Lacking officially sanctioned volume criteria, applying such pseudo-surface contamination limits has become the de facto criteria for nearly all release decisions across the nuclear industry. This approach may have been adopted out of necessity, but there is nearly universal acceptance that its use poses few risks to radiation workers or the public. The authorized surface contamination limits of 10 CFR 835 were specifically set low enough to minimize risks associated with varied and diverse exposure pathways. However, this is essentially a model, and like any model, it has its limitations. In particular, it cannot account for highly heterogeneous activity distributions in materials or distinguish removable from fixed contamination.

In most cases, decisions on the appropriateness of this approach usually can be resolved by a combination of process information, some simple measurements, and calculational predictions from a standard computer model for radiation shielding. These are, after all, the same elements used to design facilities and specify radiological work permits. Measurement requirements will depend on the process information and history available for a specific material. Aside from some legacy materials with a nebulous past, the radiological history of most are known quite well. Materials potentially contaminated in a given facility will usually exhibit radiological characteristics similar to those prevailing in that facility. Screening for contamination can then focus on the most easily detectable radionuclide in a facility's known distribution.

This usually involves the ubiquitous and easily measured gamma-emitters such as Cs-137 (Ba$137 \mathrm{~m}$ ) for fission products, and Am-241 for transuranics. The gamma flux presented to a detector from these radionuclides will depend on the physical and chemical composition of the material in question, as well as a host of measurement geometry and shielding considerations. Hence, the need for a computer model to quickly calculate these effects on the measured flux, and to answer the many "What if?" questions that must be asked to cope with potential unknowns. 
The past use of this approach in the release of tens of thousands of used railroad crossties, as well as its planned use for classification and disposal of other appropriate materials at SRS, is described below.

\section{Factors Affecting Radiological Screening of Materials}

Measurements of the amount of radioactivity contained in vessels or packages typically encountered in field situations are usually very different from ones in the laboratory. The radiation flux reaching any point in space, where an appropriate detector is positioned to respond, depends on many variables. These include type of radiation and energy, measurement distance, source size and shape, the source distribution and matrix, and shielding. A more thorough summation of such effects was recently reported by Becker et. al. [3] in a consideration of nondestructive assay technology needs for large boxed waste forms, particularly for those containing transuranic materials destined for the Waste Isolation Pilot Plant. Needs for resolving most classification and release issues are less exacting, but similar in nature.

Consider the practical case of a closed waste package of a typical 150-liter (cubical 21-inch) cardboard disposal box. The radioactive material might be present in one or many clumps anywhere in the box, or it might be distributed nearly uniformly in the matrix material. Depending on which is the case, large geometry-related uncertainties in the gamma flux are possible. Also, the bulk density and elemental constituents of the matrix material could vary widely, which will affect the intensities of escaping gamma rays at the detector, as will any other materials in between. The challenge is to identify the radionuclides and their approximate activity levels in the box from, at most, one or two gamma-ray measurements.

Considering the many unknowns of possible materials in the box, ways to bound their effects on any measurement must be at hand [3]. The physics affecting both dose and analytical flux measurements are well understood from first principles of the variables involved, and are usually found in textbooks $[4,5]$. Fortunately, computer codes are available to simplify what would otherwise be a burdensome calculational task. One code enjoying wide use in nuclear industry is MicroShield ${ }^{\mathrm{TM}} 4.21$ (or newer versions), a popular, user-friendly adaptation that runs on a personal computer [6]. Details of MicroShield, its use, and validation for a series of gamma-ray flux measurements against NIST-traceable standards may be found in reference [7].

\section{Resolving Material Classification Issues}

There are several important radiological classification issues associated with most materials that are radioactive, or potentially contaminated. How a material is classified determines how it must be disposed of, and poses very significant cost differences for those who must deal with it. The classifications loosely and broadly are 1) Transuranic (TRU) Waste: $100 \mathrm{nCi} / \mathrm{g}$ or more of $\mathrm{Np}$, $\mathrm{Pu}, \mathrm{Am}$, etc., 2) Low-Level Waste (LLW): any activity above that of naturally occurring radioactive materials and which is not in another classification [8], and 3) Unconditional-Release Material (URM): material below total surface contamination limits of $300-500 \mathrm{dpm} / 100 \mathrm{~cm}^{2}$ of $\alpha$ and $5000 \mathrm{dpm} / 100 \mathrm{~cm}^{2}$ of $\beta-\gamma$. 
This URM definition is not specifically stated in the aforementioned orders or regulations. However in practice, URM are those materials that can be released from administrative control after confirming that any residual radioactivity meets the guidelines in DOE Order 5400.5. It is possible for URM and LLW to have equal levels of contamination, but if a material is declared URM, it is, by definition 2) above, not LLW. Typical disposal costs decrease by roughly an order of magnitude each for the three classifications, with TRU being the highest and URM the lowest. Because of the costs involved, disposing of materials at the lowest defensible classification is extremely important.

The surface-contamination limit for alpha is not unambiguous. It is $500 \mathrm{dpm} / 100 \mathrm{~cm}^{2}$ in $10 \mathrm{CFR}$ 835 , but $300 \mathrm{dpm} / 100 \mathrm{~cm}^{2}$ based on DOE guidance for 5400.5 . In addition, both documents set even lower limits (20\% or less) for removable contamination, and the $\alpha$ and $\beta-\gamma$ limits apply independently. The implications of these various criteria differences are best avoided as they seldom can be resolved to complete satisfaction. This can be done by judicious selections of candidate materials, and prior checks (smears and surveys) to assure no removable contamination is present and that any alpha can be correlated with the more-easily measurable gamma activity (process knowledge and/or sample analysis).

Deciding which classification a material falls into often must be done by noninvasive or nondestructive methods. Gamma rays are usually the most applicable and sensitive measurement choice. However, before the measurement data can be used to support a classification decision, the effects of all the measurement uncertainties must be considered. Moreover, this is where a computer code for radiation modeling becomes invaluable.

By MicroShield-modeling a few extreme configuration cases of a hypothetical package of material, it is possible to bound results that could conceivably occur in a real case. This is shown in Table 1, which is a summary of MicroShield gamma-ray flux predictions. The model assumes $4 \pi$-counting conditions for varied one-microcurie distributions of either Am-241 or Cs-137 in a $53.3 \mathrm{~cm}$ (21 inch) cubical cardboard box under several different matrix/shielding extremes. Some potential radiological materials may not contain either of these activities, but many will often have some other gamma signature that can be modeled in like fashion to either the Am-241 or the Cs-137.

The numbers in Table 1 are taken directly from individual MicroShield case analyses and reveal two facts, which are fortuitous but not intuitive. First, the flux differences among the various source distributions and shields, over a wide range of gamma-ray energies, are, with the exception of steel-shrouded Am-241, fairly small. This is the result of the optimal counting geometry, which averages the effects of source location within the box, and the exclusion of dense, high atomic-number materials. Second, when buildup is considered and broad-spectrum detectors are used, the scattered flux can largely compensate for the attenuation losses due to most typical shields and sources. Buildup calculations are, however, subject to uncertainties and model results should be checked, especially for large buildup factors. Still, these two facts mean that under proper measurement conditions, uncertainties from most parametric effects of typical packages are seldom more than a factor of two or three. 
Table 1. Predicted Gamma Fluxes for Extremes in Source Distributions and Shields

\begin{tabular}{|c|c|c|c|c|c|c|}
\hline $\begin{array}{l}\text { Nuclide } \\
(1 \mu \mathrm{Ci})\end{array}$ & $\begin{array}{c}\text { Energy } \\
(\mathrm{keV})\end{array}$ & $\begin{array}{c}\text { Activity } \\
(\gamma / \mathbf{m})\end{array}$ & $\begin{array}{c}\text { Shield } \\
\text { Material/ } \\
\text { Source Shape }\end{array}$ & $\begin{array}{l}\text { Shield Thickness } \\
\text { (cm) }\end{array}$ & $\begin{array}{c}\text { Gamma } \\
\text { Flux } \\
\left(\gamma / \mathrm{cm}^{2}-\mathbf{m}\right) \\
\text { No Buildup }\end{array}$ & $\begin{array}{c}\text { Gamma } \\
\text { Flux } \\
\left(\gamma / \mathrm{cm}^{2}-\mathbf{m}\right) \\
\text { With } \\
\text { Buildup }\end{array}$ \\
\hline \multirow[t]{5}{*}{ Am-241 } & 60 & $7.97 \mathrm{E}+05$ & Air/Point & $3.17 \mathrm{E}+01$ & $6.0 \mathrm{E}+01$ & $6.6 \mathrm{E}+01$ \\
\hline & & & JC/Distributed & $5.33 E+01$ & $3.2 \mathrm{E}+01$ & $1.0 \mathrm{E}+02$ \\
\hline & & & JC/Point & $2.67 \mathrm{E}+01$ & $1.9 \mathrm{E}+01$ & $1.1 \mathrm{E}+02$ \\
\hline & & & Aluminum/Point & $1.91 \mathrm{E}+00$ & $1.7 \mathrm{E}+01$ & $1.1 \mathrm{E}+02$ \\
\hline & & & Iron/Point & $6.35 \mathrm{E}-01$ & $2.0 \mathrm{E}-01$ & $1.0 \mathrm{E}+02$ \\
\hline \multirow[t]{5}{*}{ Cs-137 } & 662 & $1.91 \mathrm{E}+06$ & Air/Point & $3.17 \mathrm{E}+01$ & $1.5 \mathrm{E}+02$ & $1.5 \mathrm{E}+02$ \\
\hline & & & JC/Distributed & $5.33 \mathrm{E}+01$ & $1.2 \mathrm{E}+02$ & $1.5 \mathrm{E}+02$ \\
\hline & & & JC/Point & $2.67 \mathrm{E}+01$ & $9.6 \mathrm{E}+01$ & $1.4 \mathrm{E}+02$ \\
\hline & & & Aluminum/Point & $1.91 \mathrm{E}+00$ & $1.0 \mathrm{E}+02$ & $1.4 \mathrm{E}+02$ \\
\hline & & & Iron/Point & $6.35 \mathrm{E}-01$ & $1.0 \mathrm{E}+02$ & $1.4 \mathrm{E}+02$ \\
\hline
\end{tabular}

The condition of a point source in air at $31.7 \mathrm{~cm}$ (half the box size plus $5 \mathrm{~cm}$ ) from the detector is shown as a reference for a minimum attenuation comparison. Shield thicknesses for aluminum and iron are chosen to show the attenuation from occasional pieces of internally contaminated equipment or containers. The only sizable effect is for the case of iron shielding of Am-241. However, such problem materials can be excluded through proper waste collection practices, and are not a serious concern.

The Job Control (JC) matrix is one most applicable to job-control waste materials, which often are produced in large quantities from radiological work. It has a hypothetical density of $0.2 \mathrm{~g} / \mathrm{cc}$ and nominally consists of $30 \%$ each of paper, polyethylene, and polyvinylchloride, and $10 \%$ of silica. This density and composition is typical of many soft wastes incidentally contaminated during work with radioactive materials and placed in boxes. Case studies of such wastes further show that density, not elemental composition, is the dominant factor affecting gamma flux. For instance, a waste matrix of $20 \%$ each of paper, polyethylene, polyvinylchloride, and silica with $10 \%$ each of aluminum and iron with a bulk density of $0.2 \mathrm{~g} / \mathrm{cc}$ has almost no effect on the JC values in Table 1; but increasing the density to $0.4 \mathrm{~g} / \mathrm{cc}$ reduces the values by about $25 \%$.

Gamma fluxes with buildup included should only be used for detectors that respond to a broad spectrum of gamma-ray energies. Those with no buildup included are appropriate for narrowspectrum detectors, or for gamma rays below about $100 \mathrm{keV}$ (Am-241) where much of the scattered low-energy spectrum may be blocked by the detector window.

\section{Real Application Examples}


Gamma fluxes on the order of those in Table 1 are not difficult to measure under proper conditions. Particularly attractive for screening decisions are plastic scintillation detectors arranged to count most of the surface area of any material passed through or placed inside a chamber (conveyor and box monitors). They can be made in large sizes, are relatively easy to shield from background, and have a high and nearly uniform detection efficiency for most gamma rays likely to be of interest.

Screening does not quantify the amount of radioactive material present, only that if any is present it must be below the screening level. It is a pass-fail decision aid rather than a measurement; a very important distinction to bear in mind. Thus, the result of the process is to reject materials potentially contaminated above an adjustable screening level and to accept the ones below.

One highly successful application of this concept at SRS was the conveyorized scanning of nearly 100,000 old, out-of-service railroad ties [9]. The potential contamination was from fission products mostly, so the ties were scanned against the $5000 \mathrm{dpm} / 100 \mathrm{~cm}^{2} \beta-\gamma$ surface limit based on a nominal $30 \%$ of the activity being detectable Cs-137. Nearly $98 \%$ of the ties passed the test (a one-minute scan of each) and were subsequently released and sold to the public. The same type of system is presently under evaluation at SRS to scan piping, scaffolding, tools, and other flat materials for public salvage or reuse. It is recognized that, like the railroad ties, some of these materials will be volume contaminated. But again, the purpose of the screening is to identify any contaminated material and eliminate it, so that only material with no detectable activity will be released. Only materials having a measurable gamma activity (surface or bulk), if contaminated, are candidates for screening.

A six-sided box monitor is also in testing at SRS for similar classification and release decisions relating to certain soft waste steams. Considering the performance characteristics of such a monitor and the size and allowable contents of candidate packages, comparisons to Table 1 can easily determine if such a screening method is justified and defensible.

For instance, cubical cardboard boxes of about 150-liters are often used for initial waste collection. The SRS box monitor for such waste has about $18,000 \mathrm{~cm}^{2}$ of detector area and a screening limit of about 1200 counts per minute. Here, screening limit refers to a high probability of detecting any gamma activity that would exceed five times the square root of the system's ambient background rate. The intrinsic gamma efficiency for plastic scintillators is about $5 \%$ at $60 \mathrm{keV}$ and about $10 \%$ between 100-1500 keV. Screening limits expressed on an areal basis for either Am-241 or Cs-137 are the relevant numbers for comparisons to Table 1. Applying the detector area and efficiencies the screening limits are: $1.3\left((1200 \mathrm{c} / \mathrm{m} \mathrm{x} 20 \mathrm{\gamma} / \mathrm{c}) / 18,000 \mathrm{~cm}^{2}\right)$ and $0.7 \mathrm{\gamma} / \mathrm{cm}^{2}-\mathrm{m}$, respectively. By comparison, the railroad tie scanners in reference [9] routinely achieved a screening limit of $3.5 \mathrm{\gamma / \textrm {cm } ^ { 2 }}-\mathrm{m}$ for Cs-137, with only four smaller detectors and less shielding than the box monitor has. Considering that the Table 1 values are for a box activity of 1 $\mu \mathrm{Ci}$, activities of about $50 \mathrm{nCi}$ of $\mathrm{Am}-241$ and $5 \mathrm{nCi}$ of Cs-137 are detectable by screening for a variety of box contents and sizes. 


\section{Low-Level vs. Transuranic Waste}

Several DOE sites, that have processed weapons or lower grade $\mathrm{Pu}-239$, could use such a monitor to quickly screen and segregate stored drums and boxes of soft waste which must be classified as either TRU or LLW. Considering the low abundance of gamma rays produced by any of the plutonium isotopes, screening possibilities would seem bleak. But $\mathrm{Pu}-241$ is the major activity in all plutonium-containing wastes, except Pu-238 (heat source) material. Stored for more than a few weeks, Am-241, a prominent gamma emitter, rapidly builds up from the decay of the Pu-241. After as little as one month, weapons-grade waste at the TRU limit of $100 \mathrm{nCi} / \mathrm{g}$ will contain about $12 \mathrm{pCi} / \mathrm{g}$ of Am-241. Fuel or reactor-grade plutonium waste would contain significantly more.

For month-old waste packages weighing as little as 15 kilograms, the total Am-241 content would be about 0.18 microcurie. The no-buildup values in Table 1 show that gamma fluxes for a box containing $0.18 \mu \mathrm{Ci}$ of Am-241 are well over the scanner's $1.3 \gamma / \mathrm{cm}^{2}-\mathrm{m}$ screening limit for all but the $0.635 \mathrm{~cm}(0.25 \mathrm{inch})$ iron-shielded point-source case. If approximate plutonium isotopics are known, rapid screening of boxed or drummed TRU wastes that are more than a month or two old is quite doable. Results of one-minute counts, even with the various uncertainties mentioned above, could allow the quick segregation of many plutonium waste into LLW and TRU piles for appropriate characterization and disposal.

\section{Unconditional Release of Salvageable Material}

Waste reduction realizes the biggest savings in disposal costs. This can come from a measurable way to decide what is URM rather than LLW. At SRS, large volumes (thousands of cubic meters) of soft waste and salvageable materials are generated annually. Past and present measurement experience leave little doubt that the majority of this is clean. Salvageable materials are those that are durable and suitable for reuse or resale. If tainted, they usually have only surface contamination, and can be easily cleaned if necessary. These materials can be released by demonstrating that if any activity is present, it does not exceed the $5000 \mathrm{dpm} / 100 \mathrm{~cm}^{2}$ fixed surface contamination limits.

Scaffolds, certain pipes, sheet metal, and hand tools are some of the attractive items that can be easily screened on a surface contamination basis. Because these are usually relatively flat, conveyor-type screening is the fastest and simplest route to release. Passing the material between two or more narrowly spaced detectors is a frequent counting arrangement. This allows the highest counting efficiency and simplest modeling because attenuation effects can be largely ignored. The SRS decontamination facility recently purchased a Conveyorized Waste Monitor (CWM) [10] and it is now being tested and evaluated for the unconditional release of hand tools. Tools are perhaps the most difficult URM to screen because of their metal thickness, crevasses, and small sizes that preclude helpful averaging allowable for pieces larger than a square meter.

The tools all come from areas where waste characterization identifies unseparated and aged fission products as the dominant radiological contaminant. Furthermore, they have all been blasted to eliminate most of any removable contamination that might be present. Few of the tools are larger than $100 \mathrm{~cm}^{2}$, so the applicable release criterion is about $1600 \mathrm{dpm}$ of Cs-137 (1/3) of 
the $5000 \mathrm{dpm}$ in the aged fission products) as a small or point source. The CWM has ten plastic scintillation detectors ( 5 above and 5 below an expanded metal conveyor belt) which respond to beta and gamma rays. The beta response of the detectors is variable and a problem in the room environment where the CWM is located at SRS. Radon in the air of the large, drafty, and relatively open concrete room is attracted by the static charge that can buildup on many materials. Radon was also a frequent problem for the railroad tie screening when this outdoor operation had to suspend counting at times of rain [9]. So it was necessary to use thin, covered metal trays to prevent the variable radon-induced beta activity clinging to tools from reaching the detectors and causing spurious alarms. In this configuration, each of the detectors has a $10 \%$ counting efficiency for Cs-137 and a background of about $50 \mathrm{cps}$. Opposite pairs of detectors also are summed which gives an efficiency approaching $20 \%$ and 100 cps background.

A 1600 dpm Cs-137 source can be expected to produce, at most, about $2.3 \mathrm{cps}$ in a summed pair of CWM detectors. The detector pair would have background of $100 \mathrm{cps}$ with a one-second standard deviation of 10 . The counting time necessary to exceed 2.3 cps by 5 standard deviations would be 473 seconds $\left(t=(5 \times 10 / 2.3)^{2}\right)$. This is nearly eight minutes and considered too slow. Instead, the screening limit has been reduced to 3 standard deviations; and a four-minute count in the CWM's stop and count mode invariably causes sum and single detector alarms for the 1600 dpm Cs-137 source at every positioning in a tray of clean tools. Preliminary tests of the instrument's continuous count mode indicate that the $5000 \mathrm{dpm} / 100 \mathrm{~cm}^{2}$ release criterion can also be met for thin materials up to nearly a meter wide at a conveyor speed of 1.25 centimeters per second.

\section{Landfill Disposal of Other Wastes}

Materials that are only potentially contaminated and have no salvage value may be candidates for landfill disposal. This is allowable if they are not likely to expose any person to more than one mrem and the affected populace to ten person-rem, and is not otherwise prohibited by applicable state or owner requirements [11]. In general, showing that a waste will not exceed the doserelated criteria is difficult to do in a generic way. This is because dose exposure depends on the assumed pathways to the affected person or populace. If contamination is limited to only surfaces, however, authorized release limits already exit, which are generally dose-conservative relative to one mrem, and only minimal ALARA considerations would be necessary for landfill disposal. Although the distinction between surface and volume contamination is not always black or white, at the activity levels that would be involved, the difference is of little consequence.

For example, the 150 -liter cardboard box above has a surface area of $17,100 \mathrm{~cm}^{2}$ and could contain just under $855,000 \mathrm{dpm}(0.385 \mu \mathrm{Ci})$ of fixed fission products evenly distributed on its exterior surfaces and meet the unconditional release criteria. Filling the box with uncontaminated job control waste would not worsen things radiologically. Conversely, disposing of a similar clean box containing job control waste that has potential fixed volume-contamination, but limited to a total level below $0.385 \mu \mathrm{Ci}$, is unlikely to pose anymore risk. Because the surface limits, in general, are already protective to below a one-mrem exposure, landfill disposal of volume contaminated waste, at or below the equivalent surface limits, should be nearly as protective in most cases. 
Pathway risks for landfill disposal are apt to be higher because of the possibility of leaching out radionuclides from the insides of soft-waste packages. However, the average contamination for such wastes-most of which are uncontaminated-will be vastly less than the screening limit, further mitigating the risk. This approach is one designed as a measurement strategy to fill a hole in present waste characterization and disposal needs for materials that are potentially contaminated in volume. Several Federal agencies are actively working on this problem and intend to proposes standards and screening limits for the unconditional release of materials. A draft of one of these, which has advanced to the review and approval stage, is ANSI N13.12, "Surface and Volume Radioactivity Standards for Unconditional Clearance". It was derived from a broad spectrum of regulatory rules and policy both in this country and abroad. It also focuses on measurement protocols and technologies that can be used to verify material compliance against specified limits. As such, the draft is a useful compilation of surface and volume contamination limits for comparison purposes.

The ANSI N13.12 draft would recommend a 30-pCi/g screening level for the unconditional clearance of volume contaminated beta-gamma emitting materials containing radionuclides such as Co-60, Sr-90, and Cs-137. Assuming a 150-liter box weighs a minimum of $15 \mathrm{~kg}$, for the methodology presented here, the screening limit on a concentration basis would equate to 26 $\mathrm{pCi} / \mathrm{g}$. Thus, this approach and that proposed in the ANSI draft arrive at virtually the same limit in totally different ways. While the ANSI N13.12 is only a draft, and may change if it is finally approved and sanctioned, it is reassuring to see such close agreement.

The values in Table 1 show that such a screening level is easily achievable. Again, it is assumed the waste contains mixed fission products with $1 / 3^{\text {rd }}$ of the total being Cs-137. The box would contain $0.128 \mu \mathrm{Ci}$ of Cs-137 and, according to the with-buildup values in Table 1, it would radiate a total gamma-ray flux of about $18 \gamma / \mathrm{cm}^{2}-$ m over its entire surface, even through $0.635 \mathrm{~cm}$

of iron. This exceeds the $0.7 \mathrm{\gamma} / \mathrm{cm}^{2}$-m value obtained above for the SRS box monitor by nearly a factor of 26. So the box monitor is capable of screening down to $5 \mathrm{nCi}$ of Cs-137, or about 1 $\mathrm{pCi} / \mathrm{g}$ of fission product activity per box. (Presently, this monitor is being evaluated at the much higher $2 \mathrm{nCi} / \mathrm{g}$ level relevant for meeting the U. S. Department of Transportation definition of radioactive.)

Waste boxes, which pass such a screening, could be disposed of in sanitary landfills with owner/regulator concurrence. At SRS, the cost saving by doing so could be several million dollars a year compared to disposal as LLW.

\section{Conclusions}

The proper classification and disposal of many solid wastes requires a measurement regime that is able to show compliance with a variety of institutional and regulatory contamination limits. Although this is not possible for all solid wastes, many do lend themselves to such measures. Several examples are discussed that demonstrate the possibilities, including one, which was successfully applied to bulk contamination. 
Despite a virtual moratorium on the unconditional release of most potential volume contaminated materials within the DOE complex, guidance relevant to Order 5400.5 allows limits in lieu of those applicable to just surface contamination to be proposed. If the potential doses to the public posed by these proposed limits are likely to be less than 1 mrem to a person and 10 person-rem to the affected populace, DOE field and program offices may allow disposal without requiring higher-level written approval. A few instances of in-lieu limits have been proposed and accepted at several DOE sites, but the process suffers for a lack of generality as to how it could or should be applied to other cases.

A draft document (ANSI N13.12) of how to better do this has been proposed, but with the process of settling comments, revisions, and concurrence, it may require several years or more before this standard is acceptable in regulatory arenas. However, comparable in-lieu limits for volume contaminated material equivalent to the 5400.5 surface contamination limits are generally conservative with respect to the $1 \mathrm{mrem} / 10$ person-rem dose risk, and can be implemented with local approval only.

To implement in-lieu limits, the measurement process for selected high-volume waste streams, which are well controlled and characterized, needs to be documented and proceduralized. This only requires cooperation and consensus between a site's radiological control and operations organization. Finally, local DOE approval must be sought. The whole process will require time and effort but it has been done before. Doing it again, given the potential cost savings, should not be an insurmountable problem.

\section{References}

1. U.S. Department of Energy, "Radiation Protection of the Public and Environment", Order 5400.5/Change 2, January 7, 1993.

2. Westinghouse Savannah River Company, "Radiological Release of Material", Radiation and Contamination Control Procedures Manual 5Q1.1 Procedure 517, Rev 0, Effective Date 04/03/97.

3. G. Becker et. al., "Transuranic and Low-Level Boxed Waste Form Nondestructive Assay Technology Overview and Assessment," Report INEEL/EXT-99-00121, Idaho National Engineering and Environmental Laboratory, (1999).

4. R. G. Jaeger et.al., Engineering Compendium On Radiation Shielding, Springer-Verlag, New York, 1968.

5. A. B. Chilton et.al., Principles Of Radiation Shielding, Prentice-Hall, Englewood Cliffs, NJ., 1984.

6. MicroShield ${ }^{\mathrm{TM}}$ Version 4.21, Grove Engineering, Inc., 15215 Shady Grove Road, Rockville, MD 20850. 
7. R. C. Hochel, "Resolving Radiological Waste Classification and Release Issues Using Material Process Information and Simple Measurements and Models", Report WSRC-TR-9700372, Rev.0, Westinghouse Savannah River Company, (1997).

8. U.S. Department of Energy, "Radioactive Waste Management", Order 5820.2A, 1988.

9. R. C. Hochel, "Automated Radiological Scanning of Potentially Contaminated Railroad Crossties for Free Release or Disposal", Report WSRC-TR-96-0176, Rev.1, Westinghouse Savannah River Company, 1996.

10. National Nuclear Corporation, 1275 Hammerwood Avenue, Sunnyvale, CA 94089.

11. DOE Guidance Memorandum, "Application of DOE 5400.5 Requirements for Release and Control of Property Containing Residual Radioactive Material", Raymond F. Pelletier, DOE Office of Environmental Policy and Assistance, November 17, 1995. 